\title{
Formação inicial do profissional em Letras \\ e a Educação Literária: anotações sobre os contextos brasileiro e português
}

Vanderléia da Silva Oliveira ${ }^{1}$

\section{Resumo}

Este artigo tem como objetivo refletir (i) sobre a formação inicial dos professores da área de língua Portuguesa e Literatura, com ênfase nos componentes que constituem a área literária, tendo como ponto de partida a análise da Proposta Pedagógica e as estruturas curriculares de um curso de Letras de uma universidade pública paranaense. Para tanto, leva-se em conta o disposto nas diretrizes curriculares nacionais para a formação dos profissionais da educação básica e as diretrizes curriculares da área de Letras no Brasil, a fim de (ii) analisar a materialização de suas propostas no curso em análise, particularmente no modo como se configura, institucionalmente, o lugar da literatura e o modus operandi do Estágio Supervisionado. Estabelece-se, ainda, (iii) breve comparativo entre o modelo de formação inicial brasileiro, considerando as referidas diretrizes, e o modelo português, centrado no Processo de Bolonha, exemplificado pelo contexto de uma universidade portuguesa.

Palavras-chave: Educação Literária. Formação inicial de professor. Estágio supervisionado. Currículo dos cursos de Letras.

\section{INITIAL EDUCATION OF THE PROFESSIONAL IN LETTERS AND LITERARY EDUCATION: NOTES ON BRAZILIAN AND PORTUGUESE CONTEXTS}

\begin{abstract}
This article has the purpose to reason (i) about the initial teacher education of Portuguese language and literature courses, with a focus on the area of literature, starting with the analysis of the Pedagogical Proposal and the curriculum guidelines of a degree in Letters of a public Brazilian university from Parana state. For this purpose, we will consider the national guidelines for the initial teacher education in Basic Education and the national guidelines for the area of Letters in Brazil. (ii) We will analyse the materialization of those guidelines within the course under analysis, particularly in the way that literature is configured and the modus operandi of the supervised practice. (iii) We will also do a brief comparison between the Brazilian model and the Portuguese one, focused on Bologna Process, with a Portuguese university as an example.
\end{abstract}

Key-words: Literary Education; Initial Teacher Education; Supervised Practice; Curriculum of Degrees in Letters

\footnotetext{
1 Doutora em Letras, na área de Estudos Literários, pela Universidade Estadual de Londrina (UEL). Professora Associada do Centro de Letras, Comunicação e Artes, da Universidade Estadual do Norte do Paraná - UENP. Realiza Estágio Pósdoutoral, na área de Educação Literária, na Universidade de Coimbra, sob a supervisão do Doutor José Augusto Cardoso Bernardes. E-mail: vances@uenp.edu.br
} 
1 Formação inicial docente e a área de Letras

Ao olhar para minha trajetória de estudos ao longo dos vinte e cinco anos em que leciono em curso de licenciatura na área de Letras, numa universidade pública, e tendo me voltado de modo mais restrito à área literária, atuando no campo da teoria literária, literatura brasileira, estágios supervisionados em literatura e sobre questões de seu ensino, é inegável que muitas dúvidas ainda persistam na minha prática docente. Uma, em especial, tem merecido atenção por se vincular à noção de educação literária e o lugar que a literatura ocupa na formação de professores. Penso se o modo como nós, professores universitários, ministramos nossas disciplinas no curso de Letras, na formação inicial, de fato prepara aqueles futuros docentes para serem mediadores de leitura literária na educação básica. Pergunto-me, ainda, em que medida o currículo contempla ou não a preparação do egresso para o trato da leitura do texto literário, integrando certa cultura literária aos saberes docentes e percebendo o lugar que ela ocupa frente à diversidade da cultura contemporânea? Tais questionamentos, evidentemente, se voltam à reflexão sobre a relação entre os conteúdos curriculares e propostas pedagógicas para o ensino de literatura em cursos de Letras.

O professor universitário, tendo função formativa, assim como a própria universidade, vêse sempre diante de um dilema: o que se espera dele? De modo amplo, a resposta apontaria para um profissional com conhecimento específico em sua área de atuação, mas, ao mesmo tempo, com formação polivalente, que permita a ele ser flexível e reflexivo para se adaptar a situações diversas, atuando não apenas no ensino como também na pesquisa. Neste sentido, os conteúdos que o docente da área de Letras seleciona para a formação de outros professores estão ligados a esta dimensão formadora da prática pedagógica e as escolhas dos conteúdos, abordagens e metodologias adotadas revelam as influências que ele próprio recebeu e que estarão presentes na formação de seu aluno, por meio das atitudes, valores e visão de mundo expostos nas práticas cotidianas em sala de aula.

Com efeito, é corrente que a formação de docentes para o ensino da língua e das literaturas de língua portuguesa, notoriamente a brasileira, tem sido objeto de estudo tanto da Educação quanto de áreas afins ou correlatas, sobretudo naquelas relacionadas com interfaces com as licenciaturas, nas últimas décadas. Por isso, constituiu-se um campo de investigação em torno desta formação dentro do qual são apontados diversos entraves que se revelam nas marcas contextuais e legislativas ao longo dos tempos. Dentre eles, a formação acadêmica inadequada, confusão conceitual nos documentos oficiais prescritivos sobre o texto literário e sua metodologia ${ }^{2}$, frequentes inadequações de sua presença no livro didático, falta de formação continuada significativa e, também, em alguns casos, falta de autonomia do próprio professor na busca pela formação.

Chamo atenção inicialmente para um deles como fator imbricado na constituição do próprio curso de Letras, que é o status do professor versus pesquisador. No texto "Historiografia, cânone e a formação do professor de literatura: ponderações sobre educação literária" ao discorrer sobre o histórico da formação dos cursos de Letras no Brasil, nascidos na década de 1930, destaco que ela

[...] traz em si a dicotomia de formar, de um lado, professores para o magistério, e, de outro, pesquisadores. Lajolo (2004) observa que, com a implantação dos primeiros cursos de Letras no país, objetivava-se "a) preparar trabalhadores intelectuais para o exercício das altas atividades culturais de ordem desinteressada ou técnica; b) preparar candidatos ao magistério do ensino secundário, normal e superior; c) realizar pesquisas nos vários domínios da cultura que constituem objeto de seu ensino. (OLIVEIRA, 2008, p. 23).

2 A propósito, analiso este tema, em conjunto com Rafael Fortes, no artigo "O ensino de literatura no Ensino Médio e os documentos oficiais" (2015). 
Ora, o que pretendo destacar é que tal gênese resultou - por longos anos e ainda hoje, embora em menor medida - na distinção entre o " investigar literatura" e o "fazer didático". De um lado, professores universitários, investigadores, produzindo conhecimento sobre o literário e, de outro, alguns poucos que se questionavam sobre como tal objeto deveria/poderia ser apresentado aos alunos da educação básica e para quê. De modo geral, os que se preocupavam com o como não mereciam tanto respeito quanto aqueles que se voltavam às altas teorias e às críticas literárias, transmitindo a várias gerações de estudantes de Letras estes saberes. É preciso ainda mencionar que outro aspecto agrava o cenário: o fato de que o curso de Letras forma, basicamente para ser professor de Língua Portuguesa, que lidará (se assim desejar) com o literário, e não exatamente para ser professor (exclusivamente) de Literatura, tendo em vista que a habilitação se volta para o currículo proposto para a educação básica. Evidentemente, há aquele que buscará carreira no meio acadêmico e, assim sendo, lidará exclusivamente com Literatura na docência no ensino superior.

De qualquer modo, licenciando-se em Língua Portuguesa, este professor terá em suas mãos o texto literário a ser apresentado aos seus alunos, daí pensarmos na especificidade de tal objeto e na necessidade de esse professor ser, sobretudo, um leitor, detentor de certa cultura literária e de repertório para trabalhar a leitura em sala de aula. É preciso, naturalmente, considerar que, como observa Carlos Reis (1992, p. 40), “[...] não é possível ensinar Literatura sem um domínio cabal, aprofundado e sistemático do fenômeno literário, da sua problematização teórica à sua evolução, das suas articulações interculturais à especificidade da sua condição de prática artística com suporte verbal". Daí a necessidade de obter conhecimentos científicos sobre a especificidade do literário e, também, a formação pedagógica. Há que se considerar, obviamente, que este mesmo professor desenvolve sua própria educação literária ao longo da vida, não sendo propriamente a Universidade que irá instrumentalizá-lo pragmaticamente para o ensino e mediação da leitura literária.

Assim posto, o professor deve ser leitor, não se deixando fragmentar em investigador, em profissional de literatura e professor de literatura como usualmente acontece, porque "todos são um só” (CEIA, 2002, p. 18). O professor leitor, profissional e investigador, não se preocupará com "o que é que aprendemos com a literatura" (p. 21), antes, perguntará “'[...] o que é que podemos nós próprios investir sobre o literário?” (p. 21).

Em entrevista recente, Carlos Ceia retoma esta posição, ao ser questionado sobre a identidade do professor, entre o ser professor e ser profissional de literatura, afirmando:

\begin{abstract}
[...] um bom professor de literatura (ou de outros saberes) tem que ser também um investigador incansável, um leitor assíduo que acompanha o melhor possível os estudos mais recentes, um pensador do seu próprio trabalho. Eu sei que é quase utópico pensar nestes termos para a maior parte dos professores fora do espaço do ensino superior, mas isso não elimina a questão essencial da formação e do seu melhor exercício. Como é que se pode ensinar literatura sem ler literatura, sem escrever sobre literatura, sem perscrutar criticamente os textos que lemos, sem agir sobre as leituras que construímos, sem discutir as leituras que recebemos de outros leitores? (OLIVEIRA, 2018, p. 219).
\end{abstract}

O dilema se dá, portanto, em torno do perfil da formação inicial de um professor na área de Letras. Minha posição é a de que, em se tratando de curso que se propõe a formar para a docência, não há como desconsiderar, de um lado, os aspectos didáticos que envolvem os componentes curriculares propostos e, de outro, há que se garantir ao mesmo tempo as especificidades nucleares de determinadas disciplinas que compõem o saber literário.

Volto, então, à questão da didática. Pelas poucas referências existentes sobre a história 
dos cursos de Letras no país e seus currículos, sabe-se que a formação pedagógica - mesmo o curso tendo o caráter, desde o início, de formar professores - não era contemplada; apenas em 1969 foi determinado pelo Conselho Nacional de Educação ${ }^{3}$ que os currículos que habilitavam ao magistério deveriam ter disciplinas pedagógicas e Prática de Ensino nas disciplinas de habilitação. No entanto, mesmo com esta obrigatoriedade, sempre houve - e ainda há - uma lacuna entre os professores da área de metodologia e prática de ensino e das disciplinas específicas. Isto porque, de modo geral, os docentes da área de Letras julgam que a formação pedagógica não é tarefa deles, deixando de lado a preocupação com "O quê" e "como" ensinar. É importante dizer que a organização proposta em 1969 permaneceu até a década de 1990, quando, após a promulgação da Lei de Diretrizes e Bases da Educaşão Nacional - LDB $n^{\circ}$ 9394/96 (BRASIL, 1996) teve início uma série de discussões sobre a reorganização dos cursos de licenciaturas no país.

O que se sabe é que, de modo geral, a tal formação pedagógica era ministrada muitas vezes por Pedagogos, vinculados a departamentos de métodos e técnicas de ensino e às práticas de ensino/estágio supervisionado, não por docentes da área de Letras. Deste modo, conteúdos, metodologias, procedimentos, nem sempre atendiam especificidades teóricas e metodológicas da área, isto porque, também deve ser dito, os docentes da área de Letras não se interessavam pela chamada "formação docente", mais preocupados com pesquisas de gabinete e suas próprias disciplinas "teóricas".

Como resultado, de modo geral, os alunos não parecem ser preparados para atuarem como professores de literatura, pois, ainda que possuam

3 A Resolução $n^{\circ}$ 9, de 10 de outubro de 1969, estabeleceu a obrigatoriedade de Psicologia da Educação, Didática, Estrutura e Funcionamento de Ensino de $2^{\circ}$ Grau, naquela época. no currículo as disciplinas de teoria da literatura, literatura brasileira e portuguesa, bem como prática de ensino ou estágio supervisionado, o ensino recai (quase sempre) sobre a história da literatura ou sobre a língua portuguesa, respectivamente. Cabe enfatizar, como já dissemos, que se compreende o papel do professor universitário como mediador entre o texto literário e o público leitor que, neste caso, é o professor em formação. Desse modo, sua própria formação deveria ter lhe dado condições de desenvolver práticas de leitura crítica, capazes de ampliar seus horizontes e de fazê-lo atribuir sentidos aos produtos culturais que o circundam, de modo que ele possa "oferecer a [seu aluno] textos mais complexos do que aqueles com que ele se depara habitualmente, mostrar-lhe como os textos se inserem numa história e como produzem sentidos e valores" (PERRONE-MOISÉS, 2002).

Com as novas legislações, decorrentes da $L D B \mathrm{n}^{\circ}$ 9394/96, é possível perceber certos avanços, pelo menos na legislação, em relação à problemática da dicotomia entre formação pedagógica e formação específica da área de Letras. Se verificarmos a trajetória do currículo dos cursos de Letras, as reformulações propostas pelas Diretrizes Curriculares Nacionais para os cursos de Letras-bem comoaResoluçãon ${ }^{\circ} 1 / 2002$, do Conselho Nacional de Educação (CNE), que tratou da formação de professores da educação básica, e a Resolução no 2/2002, também do CNE, que fixou a duração e a carga horária dos cursos de licenciatura - apresentaram a perspectiva de unir a formação teórica com sua aplicação em sala de aula. A carga horária das licenciaturas, de acordo com a Resolução n.1/2002, é de 2800 horas, englobando 400 horas de prática; 400 de estágio curricular supervisionado; 1800 horas de aulas para os conteúdos curriculares de natureza científico-cultural; e 200 horas para outras formas de atividades acadêmico-científico-culturais. 
Ao possibilitar que o currículo deixasse de ser centrado em disciplinas e passasse a ser considerado "todo e qualquer conjunto de atividades acadêmicas que integralizam um curso" (BRASIL, 2001, p.29) as diretrizes impuseram ao professor novo papel, pois além de ser responsável pelas escolhas dos conteúdos ele passou a ser, também, orientador ativo nas demais atividades que compõem a formação do graduando. Assim, não há como o docente se desvincular da natureza interdisciplinar dos componentes curriculares e do fato de que está a formar um futuro professor.

Portanto, as normas estabelecidas pela Resolução $n^{\circ}$ 2/2002, decorrente das reformulações propostas pela $L D B n^{\circ}$ 9394/96, sobretudo no que se refere à flexibilização curricular, bem como dos pareceres do CNE sobre as diretrizes curriculares para a formação de professores, representaram uma possibilidade de mudança, tendo em vista que exigiram dos cursos de Letras, assim como de outras licenciaturas, a reformulação de seus projetos político-pedagógicos sob uma perspectiva mais integrada entre as várias áreas de formação. Todavia, embora a legislação vigente acenasse para mudanças, nem sempre elas puderam ser concretizadas no espaço do cotidiano acadêmico.

De todo modo, os currículos foram revistos e implementados, sendo que muitos deles já consolidaram o currículo pleno (ciclo de pelo menos 4 anos) com a conclusão de pelo menos uma turma a ele vinculado. Entretanto, em 2015, passados pouco mais de 10 anos da divulgação e implementação pelos cursos daquelas regulamentações, novas orientações foram divulgadas. É importante observar que, recentemente, a propósito da formação inicial em nível superior (cursos de licenciatura, cursos de formação pedagógica para graduados e cursos de segunda licenciatura) e da formação continuada, as diretrizes foram reformuladas a partir da Resolução
CNE/CP 02/2015, que define as Diretrizes Curriculares Nacionais para a formação inicial em nível superior (cursos de licenciatura, cursos de formação pedagógica para graduados e cursos de segunda licenciatura) e para a formação continuada.

Esta nova regulamentação tem demandado aos cursos de licenciatura a reformulação de seus currículos a fim de aplicarem as alterações propostas, particularmente no que se refere ao mínimo de quatro anos de formação, com 3.200 horas (sendo 2.200 horas de conteúdo formativo; 400 horas de estágio; 400 horas de prática como componente curricular; 200 horas de atividades teórico-práticas de aprofundamento em áreas específicas de interesse dos estudantes), entre outras especificidades. Prevista para ser atendida no prazo de dois anos (até julho de 2017), houve alteração da data ampliando-se, pela Resolução $\mathrm{N}^{\circ}$ 1, de 9 de agosto de 2017, para três anos a contar da data inicial, a readequação obrigatória dos cursos. Sendo assim, a readequação obrigatória dos cursos se dará a partir de julho de 2018.

Basicamente, em termos de carga horária, a mudança se dá de 2800 horas de currículo mínimo para 3200, mas a configuração da estrutura das práticas, estágio e atividades teórico-práticas permanece igual, e o prazo mínimo de integralização muda de três para quatro anos letivos. As diretrizes propõem a ênfase na necessidade da formação continuada, para além da inicial, como fundamental para o exercício profissional docente. Mantém-se a proposta de uma concepção de currículo como:

[...] o conjunto de valores propício à produção
e à socialização de significados no espaço
social e que contribui para a construção da
identidade sociocultural do educando, dos
direitos e deveres do cidadão, do respeito
ao bem comum e à democracia, às práticas
educativas formais e não formais è à orientação
para o trabalho (BRASIL, 2015, p. 2).

Pressupõe-se, então, que os cursos de licenciatura levem em conta, na reorganização de suas propostas, uma concepção ampla e 
contextualizada da educação. Observo que, de modo geral, os cursos aguardaram a elaboração e aprovação da Base Nacional Comum Curricular (BNCC) aprovada em 20 de dezembro de 2017, e que deve ser efetivada até o início do ano letivo de 2020 na rede básica, após esta reestruturar suas propostas, uma vez que deverá atender às demandas por ela estabelecida para a formação de professores. Se a BNCC será referência para a reformulação dos currículos pelos estados e municípios a fim de adequar os projetos pedagógicos de suas escolas é irremediável, portanto, que a Universidade atente ao disposto para a área de Língua Portuguesa nela descrita $^{4}$ de modo a reconfigurar também seus currículos, tendo em vista o compromisso com a articulação entre a Universidade e a Educação Básica.

De qualquer maneira, o que se espera, de acordo com as novas $D C N$, é que o egresso da

[...] formação inicial e continuada deverá possuir um repertório de informações e habilidades composto pela pluralidade de conhecimentos teóricos e práticos, resultado do projeto pedagógico e do percurso formativo vivenciado cuja consolidação virá do seu exercício profissional, fundamentado em princípios de interdisciplinaridade, contextualização, democratização, pertinência e relevância social, ética e sensibilidade afetiva e estética, de modo a lhe permitir: o conhecimento da instituição educativa; a pesquisa; atuação profissional no ensino, na gestão de processos educativos e na organização e gestão de instituições de educação básica. (DOURADOS, 2015, p. 307).

Por fim, ciente de que há diversas polêmicas e lacunas (aqui deixadas à parte) a serem preenchidas, a propósito dos procedimentos de elaboração e

\footnotetext{
4 No espaço deste artigo não é possível tratar desta questão, dentre tantas, o que demandaria ampla análise do domínio intitulado Educação Literária, por exemplo, como um dentre os cinco eixos que estruturam a área de Língua Portuguesa para o ensino fundamental. Também, do ponto de vista de política educacional, outro exemplo é o da discutível proposição da BNCC, tendo em vista o modo como muito do que está nela configurado se alia a princípios outros como aqueles vinculados à sistemas e modelos de avaliação de larga escala, ao formato proposto para a reformulação do Ensino Médio, e, ainda, das amarras que vão se impondo à Universidade para que seus currículos sejam revistos a partir de tais políticas para o atendimento destas normativas.
}

aprovação dos diversos documentos referenciados, fato é que o movimento em torno das reformas curriculares, desde a promulgação da $L D B / 96$, tem resultado em intensa discussão sobre as políticas de formação de professores para a educação básica, o que, de fato, levou à necessidade de se alterar currículos e estabelecer perfis docentes qualificados com a nova ordem social.

É preciso mencionar, ainda que não seja foco de análise, que neste processo de políticas para a formação docente, importante contributo se deu com o Programa Institucional de Bolsas de Iniciação à Docência (PIBID), criado em 2007 e reorganizado (embora muito discutível) em sua concepção em 2018. O programa é mantido pela Coordenação de Aperfeiçoamento de Pessoal de Nível Superior (Capes) e tinha por objetivo provocar mudanças qualitativas no âmbito da formação de professores com impacto na educação básica em todas as regiões do Brasil. Ao longo do período 2007-2017, o programa buscou a revitalização das licenciaturas, seja pelo compartilhamento de práticas formativas entre as diversas áreas de conhecimento; pela ampliação dos espaços de discussão sobre as práticas docentes; pela interlocução das instituições de ensino superior (IES) com as escolas e com a comunidade; pela vivência dos licenciandos com as comunidades escolares sob a supervisão de professores que integram o programa, os quais não somente são levados a ressignificar suas práticas educativas, mas também a atuar como coformadores; e, sobretudo, pelo interesse na melhoria da qualidade do ensino com práticas docentes diversificadas e interdisciplinares. Desse modo, os desafios postos pelo cotidiano das escolas tornaram-se objetos de investigação para a pesquisa e para a construção de alternativas de intervenção que, por sua vez, desdobraram-se em experiências formativas, as quais ampliam, intensificam e reforçam o diálogo das escolas com as IES. 
Para 2018, numa política do Ministério da Educação para a formação docente, recentemente lançada (março deste ano), o referido programa passa a destinar-se aos alunos das primeiras séries do curso e se alinha, de certo modo, ao novo Programa intitulado "Residência Pedagógica", no qual os alunos das últimas séries se tornam residentes vinculados à prática de estágio supervisionado. Apenas para ilustrar a proposta de articulação (e aproximação) com a política de aproximação entre as instâncias Universidade-secretarias de Educaçãoescolas da rede básica, transcrevo os objetivos do Programa:

I. Aperfeiçoar a formação dos discentes de cursos de licenciatura, por meio do desenvolvimento de projetos que fortaleçam o campo da prática e conduzam o licenciando a exercitar de forma ativa a relação entre teoria e prática profissional docente, utilizando coleta de dados e diagnóstico sobre o ensino e a aprendizagem escolar, entre outras didáticas e metodologias; II. Induzir a reformulação do estágio supervisionado nos cursos de licenciatura, tendo por base a experiência da residência pedagógica; III. Fortalecer, ampliar e consolidar a relação entre a IES e a escola, promovendo sinergia entre a entidade que forma e a que recebe o egresso da licenciatura e estimulando o protagonismo das redes de ensino na formação de professores. IV. Promover a adequação dos currículos e propostas pedagógicas dos cursos de formação inicial de professores da educação básica às orientaçõ̃es da Base Nacional Comum Curricular (BNCC, sendo que um de seus objetivos é justamente o de "induzir a reformulação do estágio supervisionado nos cursos de licenciatura, tendo por base a experiência da residência pedagógica".

Como se percebe, para destacar apenas o inciso II, é intenção do Governo aliar a residência a uma reformulação dos estágios dos cursos de licenciaturas, o que, de certo modo é polêmico, tendo em vista, de um lado, a autonomia universitária para a gestão de seus currículos e, de outro, a gestão do MEC que, assim concretizada,

5 EDITAL CAPES $\mathrm{n}^{\circ}$ 06/2018. Disponível em: http://www.capes.gov.br/images/stories/download/ editais/01032018-Edital-6-2018-Residencia-pedagogica.pdf Acesso em: 6 de março de 2018. impõe certo controle sobre as ações de formação docente pelas universidades.

Polêmicas à parte, o que procurou-se demonstrar, abarcando vários temas, que se relacionam à formação do profissional da área de Letras, ainda que sem aprofundá-los, é o fato de que o contexto brasileiro tem revelado, nos últimos vinte anos intensas reflexões e ações em torno da formação inicial docente. Se os resultados têm sido todos positivos ou não, se têm dado conta de resolver os problemas vinculados ao tema, certamente não há como aferir, ainda. De qualquer modo, todas elas têm sido importantes para dar nova roupagem e propósito ao curso de Letras, demandando quebra de paradigmas - como o que apontei em torno da dicotomia entre pesquisador e professor - e exigindo do professor universitário um novo posicionamento. Sob este aspecto, julgo relevante passar os olhos sobre a experiência derivada da reformulação curricular abaixo descrita.

\section{O currículo em foco, um exemplo}

\begin{abstract}
Selecionei para considerações, especificamente quanto ao campo literário constituído pelo currículo em vigor, bem como o modo de realização do estágio supervisionado obrigatório, o curso de Letras, com habilitação dupla para a Língua Portuguesa e suas Literaturas e a Língua Inglesa e suas Literaturas, da Universidade Estadual do Norte do Paraná, campus Cornélio Procópio, que o oferta de modo presencial desde 1966.
\end{abstract}

O currículo em tela foi implantado em 2013, com total de 3600 horas de formação, atendendo às diretrizes e recomendações em vigor naquela altura, e sua primeira turma de egressos se consolidou em 2016. Além do atendimento às exigências legais, o currículo implementado levou em conta análise da proposta anterior, destacando dentre outros aspectos, os seguintes pontos: 
[...] positivos:

a) a busca de uma distribuição mais equânime entre as áreas de Língua Portuguesa e Literaturas e Língua Inglesa e Literaturas;

b) a experiência de estágio diretamente ligada a práticas escolares ancoradas em teorias estudadas em sala de aula;

c) a presença de alunos de graduação, em função de trabalho de conclusão de curso e iniciação científica, em projetos de pesquisa e extensão;

d) a busca crescente dos egressos por cursos de pós-graduação lato sensu e stricto sensu;

e) a qualificação positiva dos professores ingressantes na rede de educação básica pública.

Como pontos negativos, é preciso ressaltar:

a) a disparidade, embora combatida, entre o atendimento às áreas de Língua Portuguesa e Literaturas e Língua Inglesa e Literaturas;

b) a falta de flexibilidade do currículo gerada tanto pelo reduzido número de professores, quanto pelo exíguo espaço disponível na grade;

c) a ausência de maior estímulo a projetos de ensino por falta de infraestrutura mais adequada;

d) o atendimento coletivo de grande número de estagiários, sobrecarregando o corpo docente e inviabilizando maior proximidade com as escolas da rede de educação básica. (PPC Letras, 2012, p.8-9).

A análise indicou o redimensionamento, também, de questões pedagógicas, nomeadamente aquelas relacionadas à oferta de disciplinas eletivas (opcionais) - tais como aquelas ofertadas em função de duas Leis: a Lei 10.639, 09/01/2003, e a Lei no 10.436, de 24/04/2002, e Decreto $n^{\circ} 5.626$, de 22/12/2005, Literatura Africana e Língua Brasileira de Sinais (LIBRAS), respectivamente. Assim, passaram a compor, por seu caráter pedagógico específico, o currículo efetivo para cumprir a função de possibilitar ao discente uma visão mais detalhada dos encaminhamentos teóricos presentes nas linhas de pesquisa e nas disciplinas regulares do curso. No caso da área de Libras, esta passou a ser ofertada no último ano do curso; quanto à Lei 11.645, conhecida como "Lei Afro", houve redimensionamento em todas as disciplinas para que o tema fosse articulado transversalmente:

[...] na disciplina de Língua Portuguesa I, [insere-se] a história da Língua Portuguesa em outras comunidades falantes do idioma. Em Linguística, o foco se dá sobre aspectos fonéticos dessas comunidades, algumas particularidades no uso da Língua Portuguesa entre outros povos, notoriamente africanos e asiáticos. Quanto à língua estrangeira, a disciplina Língua Inglesa Básica também abarcará aspectos do idioma falado em outras comunidades de falantes, como na África do Sul, por exemplo. $\mathrm{Na} 2^{\mathrm{a}}$ série, a disciplina de Literatura Portuguesa I, tal como a de Literatura Portuguesa II, na $3^{a}$ série, abarcará as relações entre ex-metrópole e ex-colônias no contexto literário. Quanto à formação docente, as disciplinas Formação do Profissional em Letras, na $2^{\mathrm{a}}$ série, Formação do Professor em Língua Portuguesa, Formação do Professor em Literaturas de Língua Portuguesa e Formação do Professor de Língua Inglesa e Literaturas, na $3^{\mathrm{a}}$ série, abordarão aspectos étnicos e sociais referentes à perspectiva de uma atuação docente frente aos desafios multiculturais brasileiros. Esses desafios serão objetos teóricos das aulas de Sociolinguística, inseridas na $4^{\mathrm{a}}$ série. No caso da Literatura Infantil e Juvenil, a abordagem terá como foco a percepção de questões identitárias em textos direcionados para crianças e jovens. (PPC Letras, 2012, p. 10).

Especificamente na área literária, as disciplinas introduziram leitura de textos que refletissem elementos multiculturais em caráter universal, também apresentando a problemática das questões étnicas e sociais. Igualmente, outras disciplinas com foco no literário deveriam apresentar ao debate textos que apresentassem as diferenças culturais brasileiras e portuguesas.

Destaco, com outra perspectiva, a disciplina "Formação do profissional em Letras", com carga horária de 72 horas, ofertada na segunda série e se propõe a discutir o que segue:

Ementa: As licenciaturas no Brasil. Os cursos de Letras - história e legislação. Perfil do egresso e mercado de trabalho. Educação no Brasil: aspectos históricos, sociais e teóricos. Questões étnicas em sala de aula. Formação docente: aspectos teóricos e práticos. O trabalho docente: reflexões teóricas e aplicadas. Aula: um gênero da atividade docente. Avaliação interna e externa do aprendizado. Empreendedorismo. (PPC Letras, 2012, p. 23). 
Percebe-se, com tal inclusão, a preocupação positiva do colegiado do curso em trazer à cena o debate sobre o profissional da área de Letras, a fim de promover o contato com temas relevantes para sua formação crítica e autônoma, levando-o a refletir sobre o momento presente.

Outro aspecto positivo da proposta é o a da possibilidade, tendo em vista se tratar de um curso com dupla habilitação, do aluno optar desde a primeira série pelas áreas de maior interesse, ao concentrar sua formação em uma das línguas, Português ou inglês. Embora haja um núcleo comum para todos, o currículo prevê uma bifurcação, a partir da segunda série, em algumas disciplinas de formação específica que permitirão ao aluno mais bem dimensionar sua formação. $\mathrm{Na} 2^{\mathrm{a}}$ e na $3^{\mathrm{a}}$ séries, ele pode optar entre cursar disciplinas na área de Língua Portuguesa ou de Língua Inglesa. Na quarta série, por sua vez, são ofertados dois grupos de disciplinas eletivas, tendo em vista que no primeiro grupo o graduando deve optar por disciplinas literárias de caráter geral, que contribuam para sua formação como leitor e mediador de leitura de forma ampla; no segundo grupo, deve optar por uma disciplina literária na área das Literaturas de Língua Portuguesa ou por uma na área de Literaturas de Língua Inglesa. Tal estratégia revela que, embora ainda não seja possível ofertar um rol de optativas e/ou eletivas mais amplo, que seria ideal para atender à demanda dos alunos, este formato tem a vantagem de permitir uma abertura mínima para que o discente realize um direcionamento em seu processo formativo.

Numa perspectiva global, depreende-se que a proposta deste curso atendeu ao estabelecido pelas diretrizes nacionais, vez que introduziu certa flexibilização, dentro dos limites impostos pela distribuição da carga horária já definida no documento e tendo em vista se tratar de curso de dupla habilitação, incorporou, pelo menos em suas ementas e modo de abordagem, as discussões em torno da lei Afro e da Libras, bem como de outros aspectos socioculturais; trouxe à cena a necessidade de fazer o aluno pensar sobre sua profissionalidade; criou possibilidades para que o aluno possa se inserir em atividades culturais e científicas; e ampliou a perspectiva de compreensão sobre o estágio supervisionado, apresentando-o numa proposta mais real e reflexiva, como tratarei mais adiante. Antes, porém, focalizo o olhar sobre a presença do literário a partir de seus componentes curriculares.

\subsection{A presença do literário}

Este tópico leva em conta o pressuposto de que o professor de língua e literatura é o mediador entre o texto e o leitor no processo de educação literária. Espera-se, então, que as disciplinas obrigatórias para a formação inicial do licenciado em Letras apresentem a ele elementos que o habilitem a promover o que entendemos por letramento ideológico no trato com o texto literário na sua prática docente.

A busca da Universidade, quanto às Licenciaturas, deve focar-se na proposição de uma formação que garanta aos futuros professores da Educação Básica o uso de referenciais teóricos e ferramentas metodológicas que possam elevar o nível da educação realizada nas salas de aulas brasileiras. Em pesquisa realizada em nível de doutoramento - voltado para a investigação da disciplina de Literatura Brasileira nos currículos de Letras - identificamos que "[...] a ausência de reflexão sobre o que é educação literária revela a ineficácia do ensino de Literatura Brasileira na graduação, considerando que o estudo enciclopédico e informativo apenas afasta o graduando do letramento literário" (OLIVEIRA, 2008, p.30). Embora se esteja tratando do processo de esgarçamento entre a produção do saber e sua reprodução nas salas de aula, especificamente na 
área dos estudos literários, é possível também afirmar que este descompasso igualmente se apresenta no espaço de formação dos professores de língua materna.

No currículo em análise, a área de Literatura está contemplada no âmbito da formação geral do licenciando, conforme as diretrizes curriculares da área, com os seguintes componentes obrigatórios: Teoria da Literatura I, Teoria da Literatura II, Literatura Brasileira I, Literatura brasileira II, Literatura Brasileira III, Literatura Portuguesa I, Literatura Portuguesa II, Literatura Infantil e Juvenil, Literaturas de Língua Inglesa I, Literaturas de Língua Inglesa II, o que indica áreas basilares para a formação. Totaliza-se, pois, a carga de 792 horas, ao longo da primeira à quarta séries.

Além dos componentes referidos, conforme registra o Projeto Pedagógico do Curso, na

[...] quarta série, serão ofertados dois grupos de disciplinas eletivas, tendo em vista que no primeiro grupo o graduando deverá optar por disciplinas literárias de caráter geral, que contribuam para sua formação como leitor e mediador de leitura de forma ampla; no segundo grupo, deverá optar por uma disciplina literária na área das Literaturas de Língua Portuguesa ou por uma na área de Literaturas de Língua Inglesa, conforme oferta do Colegiado de Curso. (PPC Letras, 2012, p. 10).

Trata-se daquela escolha mencionada no item 2, que é feita pelo aluno por aptidão das áreas. Assim, soma-se o total das disciplinas opcionais na última série do curso, na área literária com a escolha de duas delas, com 72 horas cada, dentre Fundamentos da Crítica Literária, Clássicos da Literatura Universal, Estudos Culturais, Dramaturgia Brasileira, Literatura Portuguesa Contemporânea, Poesia Brasileira Contemporânea, Romance Brasileiro contemporâneo, Literatura de Língua Inglesa, tradução e adaptação: aspectos da literatura comparada, Literatura de Língua Inglesa e os gêneros virtuais: análise e produção de textos literários em ambientes virtuais, Oficina de produção e compreensão de textos literários em língua Inglesa: poesias, Oficina de produção e compreensão de textos literários em Língua Inglesa: contos. Deste modo, no âmbito do curso de 3.600 horas, o licenciando cumpre, efetivamente, 936 horas de componente curricular específico na área de Literatura, ou seja, 26\%.

Em relação à formação literária, ainda que com enfoque pedagógico, na proposta em vigor também foi inserida um importante componente curricular: a disciplina de "Formação do professor em literaturas de Língua Portuguesa”, com forte vinculação à área de estágio, como suporte para as séries seguintes nas quais o Estágio Obrigatório se desenvolverá. Também com 72 horas, ela se realiza na $3^{\text {a }}$. série e propõe o estudo sobre:

Ementa: Conceito de literatura na escola. Literatura, ensino e políticas públicas. Leitura e letramento literário. Metodologias de ensino de literatura. A literatura e os materiais didáticos. Representações literárias e o ensino de literatura - questões sociais e étnicas. (PPC Letras, 2012, p. 24).

A disciplina citada soma-se à de "Teoria da Aprendizagem e do Desenvolvimento" e "Formação do profissional em Letras", no domínio compreendido como "Disciplinas do currículo profissional”, pela caracterização a elas atribuída de discussão de métodos e técnicas sobre questões de ensino e aprendizagem.

O que se vê, então, é a tentativa de propor um currículo a partir do qual a formação do professor possa contrariar a análise feita por Cosson, na qual ele observa certos problemas verificados em cursos de Letras:

O resultado é que as práticas interpretativas das teorias e críticas literárias são adotadas pelos professores formados em Letras sem que haja um investimento na transposição didática ou na construção de uma identidade própria para o ensino de literatura e o objetivo de formação do leitor, tal como se tem, por exemplo, com a linguística aplicada em relação ao ensino de língua. (COSSON, 2013, p.16). 


\subsection{O lugar da literatura no Estágio Supervisionado}

O estágio supervisionado, articulado com todas as disciplinas do curso, ao que parece, tem proporcionado aos alunos uma visão ampla do papel do professor na sua realidade profissional, a partir das modalidades de observação e regência de aulas. Em atendimento às legislações externas, nacionais e estaduais, bem como as regulamentações internas da Universidade, ele contempla as 400 horas em Língua Portuguesa, que são cumpridas na segunda metade do curso, $3^{\mathrm{a}}$. e $4^{\mathrm{a}}$. séries $(200$ horas em cada uma delas), a fim de habilitar o licenciando a atuar na Educação Básica, nos níveis de Ensino Fundamental II e Ensino Médio. Registre-se que, neste caso, há ainda o estágio para a segunda habilitação, com 300 h, em Língua Inglesa, que segue os mesmos moldes.

A operacionalização da referida carga horária se dá nas seguintes modalidades, com apresentação de relatórios, diários críticos de observação e regência e portfólio, de acordo com definição feita pelo orientador de estágio, abrangendo a terceira e quarta séries do curso, para a área de Língua Portuguesa e Literatura: 1) regência 40 horas; 2) observação, 20 horas; 3) levantamento do contexto educacional, 40 horas; 4) análise de material didático, 40 horas; 5) elaboração de material didático, 80 horas; 6) Leituras teóricas e aplicadas, 80 horas; 7) Relatórios/Portfólio, 40 horas; 8) reunião de Grupos de estudos e orientações, 60 horas.

Observa-se, ainda, que o licenciando pode solicitar o abatimento de carga horária, optando por uma das seguintes possibilidades, se aplicável: a) alunos que lecionam com contrato temporário na rede estadual; b) alunos que participem do PIBID; c) alunos estagiários bolsistas do PIBID na mesma disciplina de estágio; d) alunos que participem de projeto de extensão na área.
Todavia, ainda que a estrutura proposta tenha correspondido a algumas das demandas estabelecidas pelas diretrizes e também à análise do currículo anterior feita pelo colegiado, a fim de buscar maior integralização das atividades em consonância com a teoria e prática, é preciso dizer que, no que se refere à Literatura, são poucos os graduandos que desenvolvem suas regências com foco nesta área.

Para análise deste "sintoma" é preciso levar em conta fatores que extrapolam os limites expostos em documentos prescritivos. Ou seja, não basta que a proposta pedagógica do curso estabeleça, direcione, oriente para um estágio integrado. Há questões outras a serem consideradas, como, por exemplo: a) poucos docentes orientadores/ supervisores de estágio que se voltem para o ensino de literatura, focando as orientações a partir de suas próprias pesquisas/áreas, nomeadamente na área de ensino de português; b) professores que são contratados por períodos determinados e que acabam atuando no estágio supervisionado sem que haja formação ou interesse nesta área, acumulando este componente com a docência em vários outros segmentos; e c) ausência de Colégio de Aplicação vinculado à Universidade para que as políticas de formação docente possam ser socializadas/integralizadas às áreas de licenciatura; para citar apenas três condições negativas.

Fato é que, mesmo havendo alguns projetos voltados para práticas literárias, percebe-se a ausência da Literatura nos estágios supervisionados. A situação é amenizada com a presença de alguns projetos de ensino que se articulam com o Estágio, como o que se vincula ao PIBID, já referido, e outro, como o de Oficinas Literárias, vinculadas ao Serviço do Comércio - SESC, inseridas na Semana Literária desse órgão, na qual alguns alunos se mobilizam para a oferta de tais oficinas. Evidentemente, por participarem destas atividades, a carga horária é computada pelo Estágio Supervisionado, mas não 
se configura como formação específica integral dos estudos.

É evidente, também, que não se propõe aqui a vivência do estágio supervisionado a partir de conteúdos apenas literários, vez que, como se disse, os alunos serão licenciados em Língua Portuguesa, sendo a literatura um dos componentes programáticos inseridos no currículo da Educação Básica. Aliás, entende-se, também, que não é possível desvincular Língua de Literatura; trata-se, tão somente, de valorizar o lugar e as potencialidades do texto literário na formação do aluno, numa perspectiva de defesa de sua relevância.

$\mathrm{Na}$ disciplina de "Formação do professor em literaturas de Língua Portuguesa”, a propósito, são tratados aspectos metodológicos para a transposição didática de textos literários, na expectativa de que na realização do estágio supervisionado, nas regências, o licenciando possa vivenciar tais propostas. Entretanto, isso nem sempre se concretiza, pois, de fato, pelos motivos já expostos, tem sido baixo o índice de regências que tenham abordado o literário.

De todo modo, a presença, por exemplo, do PIBID, com o projeto Letramento Literário, fez com que a partir dele tenham sido desenvolvidas sequências didáticas para a leitura literária em sala de aula desde 2012, ainda que não em regências vinculadas ao Estágio. Elas se voltaram para a prática sistematizada de leitura literária, a partir dos pressupostos de Cosson (2007), articuladas aos grandes eixos sobre os quais se pauta o ensino da Língua Portuguesa - leitura (literatura e demais esferas sociais), oralidade, escrita e análise linguística (PARANÁ, 2008) -, tendo como aporte de material didático a adoção de obras literárias remetidas às bibliotecas escolares pelo Programa Nacional Biblioteca da Escola/MEC (ver BRANDILEONE; OLIVEIRA, 2017). Tal experiência, que abarcou o período de 2012 a 2017, manteve em cena a necessidade de se pensar sobre Educação Literária e o que ela representa na formação do futuro professor, que lidará com o texto literário na educação básica, o que, de algum modo, pode auxiliar para que certos excessos possam ser evitados em sua prática docente.

Não à toa, retomo as ponderações de Bernardes (2005, p. 11), ao tratar do contexto português, para quem sobre a Universidade e, portanto, aos professores universitários que formam docentes da área de Letras para a Educação Básica - recai certa parcela de contribuição para os excessos e a expiação que resultaram, inevitavelmente, num apagamento do ensino da Literatura por longo período. O que se busca, então, com a prática referida é, justamente, não apenas evitar seu apagamento como também recuperar sua luz. Por isso, o desafio talvez esteja justamente no fato de que muitos desses professores universitários não se reconheçam como sujeitos diretamente ligados à formação docente e, por isso mesmo, não levam em conta a necessidade de uma didática específica para o processo de ensino de literatura em sala de aula.

\section{A formação em Portugal}

A experiência com o contexto brasileiro exposta nos itens anteriores, sobretudo no que se refere à formação inicial do professor para educação básica, especificamente na área de Letras com ênfase na abordagem da Literatura, resultou no interesse em conhecer in loco aquela que seria, por analogia, a formação em Portugal.

Ainda que os marcos contextuais e legislativos sejam muito diversos do brasileiro, a prospecção em termos das questões assinaladas no início deste texto é válida. Assim, a referência para o contato com o contexto português é a da Universidade de Coimbra, a partir de um curso da área de Letras de primeiro ciclo ofertado pela Faculdade de Letras. O olhar para outro cenário 
contribuiu para melhor compreensão do processo inicial formativo do professor, bem como permitiu que as convergências e divergências entre as práticas brasileiras e portuguesas oferecessem reflexões sobre o processo de qualificação do profissional da área de Letras. Considera-se, evidentemente, o fato de que a Faculdade de Letras de Coimbra está vinculada ao processo de Bolonha, numa alteração que se iniciou em 2006 e que implicou em mudanças nas diretrizes do ensino superior português, modificando, pois, a formação do profissional docente.

Destaca-se que o Processo de Bolonha, desencadeado pela assinatura da Declaração de Bolonha, por 29 estados europeus, em 19 de junho de 1999, a fim de unificar no espaço europeu e oferecer condições para mobilidade, conhecimento e formação de profissionais para o mercado de trabalho, impactou, certamente, no campo da formação de professores para a educação básica, como denominamos no Brasil e, em Portugal, para os ciclos de ensino. A propósito, Melo e Branco, em estudo sobre o perfil de professores no âmbito do Processo de Bolonha, após analisarem a evolução do perfil de professor em Portugal, observam que:

De um professor com perfil técnico passou a considerar-se como necessidade fundamental para dar resposta às necessidades atuais do sistema de ensino português, um professor com um perfil cada vez mais profissional capaz de se adaptar às características e desafios decorrentes da sociedade atual e que, através da sua prática, desenvolva e potencie os conhecimentos adquiridos durante a sua formação inicial. (MELO; BRANCO, 2013, p.32).

Dentre as mudanças havidas, uma delas é a da uniformização das nomenclaturas em torno de dois ciclos: o da formação inicial passa a ser denominada licenciatura, ${ }^{6}$ realizada em três anos ( $1^{\circ}$. Ciclo); em seguida o Mestrado, com mais 2 anos (2 ${ }^{\circ}$. Ciclo),

6 Observa-se que o termo licenciatura não apresenta o mesmo conceito que o usual no Brasil. Neste contexto toda graduação recebe tal designação, e não apenas os que formam para a docência. e, ainda, os estudos avançados para o Doutorado. Assim, o sujeito que tem interesse em se dedicar à docência para a educação básica, especificamente $3^{\circ}$ ciclo até o secundário, para além da formação inicial na licenciatura, deverá cursar o Mestrado em Ensino, que é o segundo ciclo da Licenciatura. A formação de professores educadores de infância e professores do $1^{\circ}$ e $2^{\circ}$ ciclos do ensino básico $\left(1^{\circ}\right.$ ao $6^{\circ}$ ano) é desenvolvida em Escolas Superiores de Educação (ESEs), no âmbito dos Institutos. Nunes e Nunes, em estudo sobre a formação inicial de professores em Portugal, resumem bem o processo, conforme abaixo:

\begin{abstract}
A regulamentação portuguesa, por meio do Decreto-Lei no. 43/2007, de 22 de fevereiro3, determina que a habilitação profissional para a docência possa ser estruturada de maneira separada nos domínios: educador de infância ou professor do $1^{\circ}$ ciclo do ensino básico $\left(1^{\circ}\right.$ ao $4^{\circ}$ ano); ou com a possibilidade de ser ofertada em conjunto nos respectivos domínios, acrescido dos professores de $2^{\circ}$ ciclo do ensino básico $\left(5^{\circ}\right.$ ao $6^{\circ}$ ano) até então realizados de forma separada. Para a educação infantil e para os referidos ciclos, define-se, ainda, uma formação profissional generalista conseguida por meio de uma Licenciatura em Educação Básica (educador de infância e professor do $1^{\circ}$ ciclo do ensino básico). Esta continuará obrigatoriamente em um curso de mestrado em ensino, acadêmico ou profissionalizante, num destes domínios. Da mesma forma é exigido a licenciatura e o mestrado em ensino em uma ou até duas áreas disciplinares para os professores do $3^{\circ}$ ciclo do ensino básico $\left(7^{\circ}, 8^{\circ}\right.$ e $9^{\circ}$ anos) e do ensino secundário para obterem a habilitação à docência, independente da área da licenciatura de base, mantendo-se, então, nesta organização, uma qualificação do professor generalista e outra de professor de disciplina. (NUNES; NUNES, 2013, p.204, destaque da autora).
\end{abstract}

A reformulação havida pelo Decreto DecretoLei $n .^{\circ} 79 / 2014$, que aprova o regime jurídico da habilitação profissional para a docência na educação pré-escolar e nos ensinos básico e secundário, sintetiza a formação que aqui nos interessa para efeitos comparativos:

Reconhece-se que ao primeiro ciclo, a licenciatura, cabe assegurar a formação de base na área da docência. E salienta-se que ao segundo ciclo, o mestrado, cabe assegurar um 
complemento dessa formação que reforce aprofunde a formação académica, incidindo sobre os conhecimentos necessários à docência nas áreas de conteúdo e nas disciplinas abrangidas pelo grupo de recrutamento para que visa preparar. Cabe igualmente ao segundo ciclo assegurar a formação educacional geral, a formação nas didáticas específicas da área da docência, a formação nas áreas cultural, socia e ética e a iniciação à prática profissional, que culmina com a prática supervisionada.

Cito, como parâmetro comparativo, enquadrado nesta legislação, o curso de Licenciatura Português, com desenvolvimento em 6 semestres (3 anos). Trata-se de curso que tem "[...] por objetivo central proporcionar uma base interdisciplinar de conhecimentos, que permita formar profissionais no domínio das Humanidades". ${ }^{8}$ Consolida 180,0 créditos ECTS ${ }^{9}$ e apresenta as seguintes competências a serem alcançadas pelo egresso:

- Capacidade ampla de expressão oral e escrita em português.- Consolidação de uma dimensão internacional da língua, literatura e cultura. - Capacidade para estabelecer relações entre a área de formação e outras áreas do saber, mais ou menos próximas. - Capacidade para distinguir entre conhecimento científico e opinião ou crença.

- Competência argumentativa, autonomia intelectual e capacidade crítica. -Capacidade para aceder à informação e para a tratar de acordo com critérios de pertinência e relevância. - Capacidade para usar de forma inovadora os conhecimentos e competências adquiridos. - Perceção do valor civilizacional das Humanidades e das competências que elas transmitem.

As saídas profissionais do curso são para: "Formação Inicial para Professor/a de Português, Leitor/a e Professor/a de Português como língua segunda, Investigador/a, Revisor/a e Coordenador/a de Edição/Publicação de textos, 7 Disponível em: < https://dre.pt/application/ conteudo/25344769> Acesso em 5 fev. 2018.

8 Disponível em: $\underline{\text { https://apps.uc.pt/courses/PT/ }}$ course/5581. Acesso em 5 fev. 2018.

9 "ECTS - European Credit Transfer and Accumulation System é um sistema de créditos europeu que permite medir o trabalho que um estudante dispende no seu curso. Para terminar um curso um estudante tem de completar um determinado número de créditos em cada uma das áreas de estudo respectivas. Quando muda de escola ou curso, os créditos completados na escola ou curso anteriores, mesmo que noutro país, podem ser aceites no novo curso/escola para que mudou". Disponível em: https://www.uc.pt/fctuc/ bolonha/referencia. Acesso em: 10 fev. 2018.
Técnico/a Superior da Administração Pública, Quadro Superior da Administração Pública, Profissional de Relações Públicas, Assessor. Outras áreas de atividade profissional, artística e cultural que envolvam profissionais de língua materna e especialistas em cultura portuguesa, no país ou no estrangeiro". O curso impõe algumas regras para a integralização do currículo pelo aluno, a partir das áreas de concentração complementar (30 ECTS) em domínio científico diferente da área de especialização, podendo ser feita em outro departamento, e mesmo fora da FLUC; Área de formação geral (24 ECTS) que serve de suporte aos estudos avançados, como é o caso das línguas estrangeiras; Área de iniciação (18 ECTS) de preparação para a transição do ensino secundário para o universitário. ${ }^{10}$

Neste curso o estudante deve contemplar 60 ECTS por ano, a partir de suas escolhas dentre o rol de componentes curriculares, entre obrigatórias e optativas. Cada uma delas corresponde a 6.0 ECTS. Há disponíveis 24 componentes, sendo 15 da área literária, 7 da área da linguística e língua portuguesa e 2 da área de cultura africana e portuguesa. Conforme o nosso interesse, verifica-se que na área literária estão disponíveis: nas obrigatórias, Literatura Portuguesa do Modernismo ao Pós-Modernismo e Literatura Portuguesa do Renascimento; nas optativas, Estudos Queirosianos, Introdução aos Estudos Literários, Literatura Portuguesa do Barroco ao Neoclassicismo, Literatura e outras Artes, Literaturas Angolana e Moçambicana, Problemas Críticos da Literatura Brasileira, Estudos Camonianos, Estudos Pessoanos, Literatura Brasileira, Literatura Portuguesa Medieval, Literatura Portuguesa do Romantismo ao Fim de Século, Literaturas São-tomense, Caboverdiana e Guineense e Teoria da Literatura.

10 Disponível em: https://apps.uc.pt/courses/PT/ programme $/ 5581 / 2018-2019$ ?id_branch $=15741$ Acesso em 10 fev. 2018. 
O que se depreende desta estrutura curricular é que o aluno possui autonomia para gerir sua formação a partir das ofertas, com flexibilização entre as áreas, e de modo a compor uma grelha de disciplinas nucleares e/ou complementares que congregam saberes, atitudes e competências específicas a serem assimilados. Todavia, observase que não há, neste ciclo, preocupação com questões formativas para a docência. Apenas, então, ao integralizar o currículo é que, agora já licenciado, o sujeito poderá seguir para o $2^{\circ}$. Ciclo, nos Mestrados Profissionais em Ensino, para obter o grau de mestre, como condição indispensável para o exercício da docência. Tal etapa, portanto, é que define a formação pedagógica para a docência na área pretendida, conforme se vê a seguir.

\subsection{Formação docente}

Ao optar pela docência, o licenciado pode escolher, por exemplo, o Mestrado em Ensino de Português no $3^{\circ}$ ciclo do Ensino Básico e no Ensino Secundário (120 ECTS). Também é possível optar pelo Mestrado em Ensino de Português no $3^{\circ}$ ciclo do Ensino Básico e no Ensino Secundário e de Latim no Ensino Secundário. Entretanto, como meu interesse é para o curso que aborde a Literatura, foco minhas considerações no primeiro deles, que apresenta como objetivos:

1. aprofundar e consolidar conhecimentos e competências em Português (Língua e Literatura) adquiridos na licenciatura, realçando temas do currículo do ensino básico e secundário; 2. aplicar conhecimentos na planificação e execução de aulas fundamentadas a nível científico, pedagógico e didático, tendo em conta especificidades de situações de ensino-aprendizagem e grupos de alunos, orientações curriculares, procedimentos e materiais adequados; 3 . compreender a dimensão social, ética e cívica da função docente e da sua disciplina e desenvolver espírito crítico e capacidade de reflexão que orientem a sua prática letiva em situações sempre novas e complexas e a sua intervenção no contexto escolar e fora dele; 4. ser capazes de comunicar e participar adequadamente na comunidade escolar; 5. reconhecer a necessidade de permanente

atualização científica, pedagógica e didática e saber pesquisar sobre aspetos relativos à prática docente, de modo a aperfeiçoá-la. ${ }^{11}$

Para a integralização do curso é necessária a aprovação nas unidades curriculares e no ato público de defesa de relatório relativo à prática de ensino supervisionada. Há 9 unidades curriculares a serem cumpridas no primeiro ano, todas obrigatórias. Diretamente vinculada à área literária é ofertada uma componente: Educação Literária. Mas, a literatura também aparece em outras duas, aliadas ao ensino de Língua Portuguesa: Didática da Língua e da Literatura Portuguesas I, Didática da Língua e da Literatura Portuguesas II. Importa destacar que os demais componentes se voltam à formação pedagógica: Língua Portuguesa: Usos, Organização Escolar e Gestão da Sala de Aula, Psicologia do Desenvolvimento e Aprendizagem, Desenvolvimento Curricular e Avaliação, Necessidades Educativas Especiais, Ética e Filosofia da Educação. No segundo ano, o mestrando deve cumprir Seminário de Português I, Seminário de Português II e o Estágio e Relatório.

Quanto ao estágio, este é realizado de acordo com os temas escolhidos pelo aluno e tem como objetivo:

\begin{abstract}
- Proporcionar aos/às formandos/as através de um plano específico de formação no domínio da habilitação para a docência experiências reais de observação, planificação, ensino e avaliação, bem como o envolvimento no largo espectro de responsabilidades que se esperam do/a docente, dentro e fora da sala de aula; - Promover o desenvolvimento profissional dos/as formandos/as visando o seu desempenho como futuros/as docentes e promovendo uma postura crítica e reflexiva em relação aos desafios, processos e desempenhos do quotidiano profissional;
\end{abstract}

- Aplicar criticamente métodos e teorias estudados na docência e na elaboração do relatório de estágio; - Aprofundar formação académica adequada às exigências da docência nas áreas curriculares ou disciplinas abrangidas pelo respetivo domínio de habilitação para

11 Disponível em https://apps.uc.pt/courses/PT/ course/5741. Acesso em 10 fev. 2018. 
a docência; - Aprofundar métodos de investigação no contexto das didácticas específicas; - Desenvolver capacidades de comunicação e argumentação. ${ }^{12}$

A disciplina "Educação literária" apresenta como conteúdo programático: "Educação literária nos Programas de Português do Ensino Básico e do Ensino Secundário - recomendações e práticas. Gosto pela literatura vs iliteracia estética. Literatura juvenil e crossover fiction. Androgogia e literatura. Literatura de língua portuguesa e literatura universal. Leitura crítica do PNL: critérios, faixas etárias". Tal conteúdo deverá possibilitar ao mestrando, ao final: "dominar os conceitos básicos tratados no programa; - dominar a história da literatura juvenil em língua portuguesa; - conhecer os clássicos da literatura universal recomendados no PNL; - adequar a seleção literária à educação de adultos; - desenvolver estratégias que fomentem o gosto pela literatura". ${ }^{13}$

Chama atenção a oferta desta componente curricular, tendo em vista que está consolidado em Portugal o chamado domínio "Educação Literária", de modo autônomo e explícito, no âmbito dos Programas e Metas Curriculares de Português do Ensino Básico (PMCP, 2015), dentre os quatro domínios de referência no $10^{\circ}$ e no $2 .^{\circ}$ Ciclo (Oralidade, Leitura e Escrita, Educação Literária, Gramática) e cinco no $3 .^{\circ}$ Ciclo (os mesmos, mas com separação dos domínios da Leitura e da Escrita). Balça e Azevedo destacam que muitos foram os fatores que levaram ao alcance desse domínio, tais como investigação científica alargada sobre formação de leitores, a própria discussão em torno da formação docente e a criação da Rede de Bibliotecas Escolares e o Plano Nacional de Leitura (2017, p. 133). Portanto, espera-se que a disciplina

12 Disponível em: https://apps.uc.pt/courses/ $\mathrm{PT} /$ unit/81125/15921/2018-2019? common_ core $=$ true\&type $=$ ram\&id=5741. Acesso em 12 fev. 2018.

13 Disponível em: https://apps.uc.pt/courses/ $\mathrm{PT} /$ unit/81124/15921/2018-2019? common_ core $=$ true\&type $=$ ram\&id $=5741$. Acesso em 12 fev. 2018. no curso de formação trate, de fato, do tema para que os futuros professores possam dominar os itens indicados na proposta programática e desenvolvam uma prática reflexiva em sala de aula.

No Brasil, o referido domínio se encontra na BNCC, recentemente aprovada, inserido dentre os cinco eixos organizadores da área de Língua Portuguesa. Aliás, a compreensão de como os dois documentos - a BNCC e os PMCP - conceituam Educação Literária e o modo como o domínio se articula ao ensino de Língua Portuguesa, pode ser tema de interessante análise, que, neste momento, foge ao escopo e limites deste texto.

Por fim, é importante destacar que as áreas de formação de professores da Faculdade de Letras da UC criaram um Núcleo de Estudos em Ensino com a finalidade de agregar a "investigação já desenvolvida no âmbito do ensino e formação de professores e fomentar desenvolvimento integrado desta área". Tem como propósito:

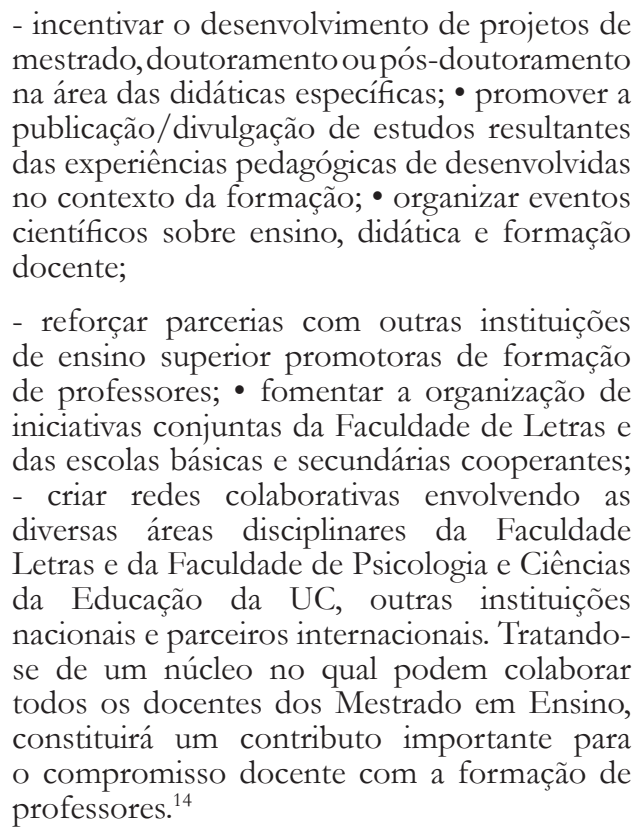

Este Núcleo, do qual fazem parte do Conselho de Formação de Professores os diretores de todos os mestrados em ensino da FLUC, tem sido importante articulador de ações formativas

14 Disponível em: https://www.uc.pt/fluc/nee/ apresentacao. Acesso em 13 fev. 2018. 
envolvendo orientadores, supervisores, mestrandos e comunidade interessada nas atividades, tais como cursos, palestras, eventos, como se vê nos objetivos acima descritos. No caso da UENP, não existe tal estrutura, apenas foi criado, em 2016, um Fórum Permanente das Licenciaturas (aqui se referindo aos 14 cursos que formam exclusivamente para docência), com total de 74 membros. O Fórum não possui poder deliberativo, pois trata-se de uma instância autônoma indicativa, com ação política fundamental, tendo a finalidade de promover a integração e o fortalecimento entre os cursos na Instituição, porém sem ação formativa como a do referido núcleo da FLUC.

Percebe-se, portanto, que a formação entre o $1^{\circ}$. Ciclo e o $2^{\circ}$. Ciclo, completada em 5 anos, comparativamente ao modelo brasileiro, que é de 4 anos, apresenta como dinâmica a separação entre formação em conteúdos nucleares da área e a visada pedagógica, o que vai na contramão do que é proposto para as licenciaturas no Brasil. Para este, o modelo é o da interface teoria-prática desde a série inicial do curso, com forte ênfase na dimensão formadora da prática pedagógica, de acordo com o disposto nas Diretrizes Nacionais, já referidas. A continuidade da formação, por sua vez, em nível de Mestrado, se dá após a graduação, por 24 meses, não havendo necessidade legal de realizá-lo para habilitação à docência, sendo que a opção pode ser por um Mestrado acadêmico (que encaminha para investigação) ou para um Profissional, nomeadamente voltado para os docentes que já estão em serviço na área ou para aqueles que seguiram a carreira na educação básica.

Sob este aspecto, a formação no contexto português centra-se, inicialmente, no conhecimento fundamental, de conteúdo a ser assimilado para, em seguida, desenvolver o saber didático sobre tal conhecimento científico absorvido, o que revela um processo formativo não integrado, pois cada ciclo rege seus objetivos e conteúdos formativos, o que pode (talvez) ser prejudicial a certos aspectos relacionados à interdisciplinaridade, articulação entre conhecimentos científicos e didático-pedagógicos, por exemplo, que acabam se esvanecendo na bipartição referida.

\section{Algumas considerações}

No breve resgate dos dois modos de formação docente, um brasileiro e outro português, respeitando-se os limites de suas especificidades históricas e documentais, pretendia-se localizar se há um lugar para o texto literário nos componentes curriculares de modo a oportunizar a integração entre teoria e prática. Ambos os exemplos contemplam em seus currículos a presença de disciplinas basilares para a apropriação do saber científico sobre a Literatura e também sobre suas produções literárias, respectivas. Pela natureza de seus modelos de formação, como se apontou, a divergência ocorre quanto à articulação com a didática e formação pedagógica sistemática, pois em uma delas a formação se dá em 4 anos sem bipartição entre ciclos, e, em outra, que é a proposta do modelo português, isso ocorre na integralização em 5 anos.

Percebe-se, ainda, que ambos os currículos almejam uma formação que ofereça certa flexibilização, de modo a oportunizar ao aluno autonomia na busca dos conhecimentos. Tal autonomia indica o desejo de se constituir um perfil de profissional consciente da necessidade de formação contínua e reflexiva, que desempenhe suas atividades com ética e respeito aos alunos, a despeito de certa precarização porque passa a profissão de professor em ambos os países e que tem, inclusive, oprimido a busca pela carreira do magistério.

De todo modo, o que se deseja para o campo da Educação, especialmente o da Literária, é a formação de profissionais críticos, reflexivos, 
pesquisadores e que busquem a mediação do conhecimento em suas práticas docentes. Desejase, também, que este profissional compreenda que sua formação é contínua e integrada com outras áreas do saber, assim como deve ser dinâmica e necessita da revisão de conceitos e estratégias para atender às demandas de cada momento históricosocial.

A concepção de que a Educação Literária é ato que potencializa a subjetividade do leitor no seu processo de formação e, por isso mesmo, ação que favorece a compreensão das produções culturais e seus desdobramentos na constituição de identidades, pode ser o ponto de partida para que os estudos sobre a Literatura e seu ensino componham nos currículos dos cursos de Letras importante parcela programática. Afinal, é importante que o docente que ministre Literatura na universidade e que assume papel fundamental no processo de mediação de leitura tenha uma visão do significado da educação literária na formação do profissional que lidará com o texto literário, valorizando a leitura crítica e participativa, dando VOz ao aluno para que este produza seu próprio discurso. A perspectiva é a de que os alunos saiam das universidades com condições de discutir literatura de modo mais efetivo e plural, sem a marca apenas da tradição ideológica canônica, mas trazendo o contemporâneo - e suas interfaces - para o diálogo entre os diferentes contextos de produção e recepção. É preciso entender que estudar literatura, como disciplina escolarizada, implica saber transitar entre os espaços que ela ocupa como objeto de estudo não propriamente literário em interface com diversas outras áreas.

É necessário, a meu ver, que os docentes universitários busquem a atualização de conhecimentos sobre metodologias do ensino da literatura e de abordagem do texto literário, valorizando os estágios supervisionados e as práticas de ensino na área, exercendo não apenas a função de pesquisador, mas também a de professor. Em torno, ainda, da necessidade de se pensar o papel do professor de Literatura em tempos contemporâneos, recorro a uma provocação apresentada por Gens, no texto "Formação de professores de literatura brasileira - lugares, paisagens educativas e pertencimentos", quando este cita Schowalter, que questiona: "[...] o que professores de literatura deveriam fazer em sala de aula em tempos de crises, desastres, tragédias, tristeza e pânico?” (2003, p.131 apud GENS, 2008). Ao pensar sobre o lugar do professor de literatura brasileira Gens alerta, por exemplo, para os ruídos do mundo que nos cercam e conduzem nossas rotinas, destacando que:

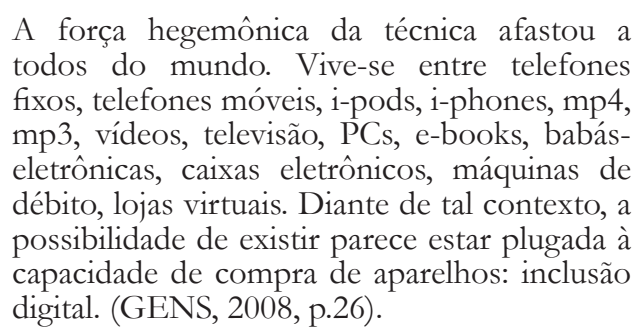

Neste cenário, questiona-se: qual o papel do profissional que lida com a literatura? Para qual escola ensinar literatura? Ou mesmo que literatura ensinar e para quê? Vale, sobre este aspecto, considerar os posicionamentos de Sarlo (2002), quando ela defende a função exercida pela arte na esfera pública, e pensar o modo pelo qual os estudos literários resgatariam o seu papel no seio das humanidades, a fim de desenvolver, de fato, a Educação Literária e defender a função social a ser exercida pelo ensino literário (e seus rumos) na sociedade contemporânea.

\section{Referências}

BALÇA, Ângela; AZEVEDO, Fernando. Educação literária em Portugal: os documentos oficiais, a voz e as práticas dos docentes. Revista Linhas. Florianópolis, v. 18, n. 37, p. 131-153, maio/ago. 2017 
BERNARDES, José Augusto Cardoso. A literatura no ensino secundário: excessos, expiações e caminhos novos. In: DIONÍSIO, Maria de Lourdes e CASTRO, Rui Vieira de (orgs). O português nas escolas - ensaios sobre a língua e a literatura no ensino secundário. Coimbra: Almedina, 2005.

BRANDILEONE, Ana Paula F. N.; OLIVEIRA, Vanderléia da Silva. O lugar do PIBID e do PNBE na e para a formação de leitores. Estudos de Literatura Brasileira Contemporânea, v. 50, p. 311-329, 2017. Disponível em: <http://www.scielo.br/pdf/elbc/ n50/2316-4018-elbc-50-00311.pdf>. Acesso em: 20 dez. 2017.

BRASIL. Congresso Nacional. Lei $n^{0}$. 10436, de 24 de abril de 2002. Brasília, 2002.

Conselho Nacional de Educação. Parecer MEC/CNE/CES $n^{\circ}$ 492/2001, de 4 de julho de 2001. Diretrizes curriculares nacionais dos cursos de filosofia, história, geografia, serviço social, comunicação social, ciências sociais, letras, biblioteconomia, arquivologia e museologia. Diário Oficial da União, Brasília, seção 1e, p. 50, 9 jul. Disponível em: < http://portal.mec.gov.br/ cne/arquivos/pdf/CES0492.pdf> Acesso em 10 jan.2018.

Conselho Nacional de Educação. Resolução MEC/CNE/CP n 02/2002, de 19 de fevereiro de 2002. Institui a duração e a carga horária dos cursos de licenciatura, de graduação plena, de formação de professores da Educação Básica em nível superior. Diário Oficial da União, Brasília, seção 1, p. 9, 4 mar.

Conselho Nacional de Educação. Resolução MEC/CNE/CP n ${ }^{\circ}$ 02/2015, de $1^{\circ}$ de julho de 2015. Define as Diretrizes Curriculares Nacionais para a formação inicial em nível superior (cursos de licenciatura, cursos de formação pedagógica para graduados e cursos de segunda licenciatura) e para a formação continuada. Diário Oficial da União, Brasília, seção 1, p. 8-12, 2 jul.

Ministério da Educação. Base Nacional Comum Curricular. Brasília: MEC, 2017. Disponível em: <http://basenacionalcomum.mec.gov.br/> Acesso em: 06 mar. 2018.
Presidência da República. Decreto $n^{\circ}$. 5626 de 22 de dezembro de 2005. Disponível em: $<$ http://portal.mec.gov.br/seesp/arquivos/pdf/ dec5626.pdf > Acesso em: 03 mar. 2018.

. Presidência da República. Lei no 10.639, de 09 de janeiro de 2003. Altera a Lei no 9.394, de 20 de Dezembro de 1996, Que Estabelece As Diretrizes e Bases da Educação Nacional, Para Incluir no Currículo Oficial da Rede de Ensino A Obrigatoriedade da Temática "história e Cultura Afro-brasileira", e Dá Outras Providências.. Disponível em: <http:// www.planalto.gov.br/ccivil_03/leis/2003/ L10.639.htm>. Acesso em: 1 fev. 2018.

. Presidência da República. Lei 11.645, de 10 de março de 2008. Disponível em: Disponível em: $\quad<$ http://www2.camara.leg.br/legin/fed/ lei/2008/lei-11645-10-marco-2008-572787publicacaooriginal-96087-pl.html $\geq$ Acesso em: 5 mar. 2018.

. Senado Federal. Lei no 9.394, de 20 de dezembro de 1996. [Lei de Diretrizes e Bases da Educação Nacional]. Estabelece as diretrizes e bases da educação nacional. Diário Oficial [da] República Federativa do Brasil, Brasília, 23 dez.

CEIA, Carlos. O que é serprofessor de literatura. Lisboa: Colibri, 2002.

COSSON, Rildo. Letramento Literário. São Paulo: Contexto, 2007.

A formação do professor de literatura - uma reflexão interessada. In: PINHEIRO, Alexandra Santos; RAMOS, Flávio Brochetto. (org.) Literatura e formação continuada de professores: desafios da prática educativa. Campinas: Mercado de Letras, 2013.

DOURADO, Luiz Fernandes. Diretrizes Curriculares Nacionais para a formação inicial e continuada dos profissionais do magistério da educação básica: concepções e desafios. Educ. Soc., Campinas, v. 36, nº.131, p. 299-324, abr.-jun., 2015.

FORTES, Rafael Adelino; OLIVEIRA, Vanderléia da Silva. O ensino de literatura no Ensino Médio 
e os documentos oficiais. Contexto, Vitória, n. 27, 2015/1. Disponível em: <www.periodicos.ufes. br/contexto/article/download/10424/7356>. Acesso em: 20 fev. 2016.

GENS, Armando F. Formação de professores de literatura brasileira - lugares, paisagens educativas e pertencimentos. Revista Fórum Identidades, Ano 2, Volume 4 - p. 21-36 - jul-dez de 2008. Disponível em: <http://200.17.141.110/periodicos/revista forum_identidades/revistas/ARQ_FORUM_ IND_4/DOSSIE_FORUM_Pg_21_36.pdf> Acesso em: dez. 2017.

MELO, Ana Souto e; BRANCO, Maria. A formação inicial de professores no âmbito do Processo de Bolonha: o caso da formação de professores de educação visual e tecnológica. Saber e Educar, n. 18, 2013. Disponível em: <http://revista.esepf.pt/ index.php/sabereducar/article/view/46>. Acesso em: 20 jun. 2017.

NUNES, Cely do Socorro Costa; NUNES, Herika Socorro da Costa. A formação inicial de professores em Portugal: hoje em dia, todo professor deve ser... Educação em Perspectiva, Viçosa, v. 4, n. 1, p. 224-237, jan./jun. 2013.

OLIVEIRA, Vanderléia da Silva. Entrevista a Carlos Ceia. Claraboia, Jacarezinho/PR, v.9, p. 212-222, jan./jun., 2018. Disponível em: < http:// seer.uenp.edu.br/index.php/claraboia/article/ view/1273/pdf>. Acesso em: 12 jan. 2018.

Historiografia, cânone e a formação do professor de literatura: ponderações sobre educação literária. In: (org.). Educaşão literária em foco: entre teorias e práticas. Cornélio Procópio: 2008. E-book. Disponível em: http://www.ccp. uenp.edu.br/e-books/uenp/2008-vsoliveira-orgeducacao_literaria.pdf> Acesso em: 10 jan 2018.
PARANÁ. Secretaria de Estado da Educação. Diretrizes Curriculares Estaduais de Lingua Portuguesa. Curitiba, 2008.

PMCP. Programa e Metas Curriculares de Português do Ensino Básico. Lisboa: Ministério da Educação e Ciência, 2015. Disponível em: <https://www. dge.mec.pt/sites/default/files/Basico/Metas/ Portugues/pmcpeb_julho_2015. pdf $>$. Acesso em: 30 jan. 2017.

PERRONE-MOISÉS, Leila. A literatura como mediação. In: CONGRESSO INTERNACIONAL ABRALIC - Mediações, 8., 23-26 jul. 2002, Belo Horizonte. Anais... Belo Horizonte: UFMG. CDROM.

PROJETO PEDAGÓGICO DO CURSO - LETRAS. Cornélio Procópio: Universidade Estadual do Norte do Paraná, 2012. Disponível em: $<$ https://pt.scribd.com/document/368122457/ PPC-Curso-de-Letras-Portugues-InglesOFICIAL> Acesso em: 1 mar 2018.

REIS, Carlos. Reflexões genéricas sobre o estatuto da didática da literatura. O Professor, n. 26 ( $3^{\mathrm{a}}$ série), Lisboa, Maio-Junho, 1992.

SARLO, Beatriz. A literatura na esfera pública. In: Marques, Reinaldo; Lúcia Helena Vilela (orgs.). Valores: arte, mercado, política. Belo Horizonte: UFMG, 2002.

Submissão: Janeiro de 2018

Aceite: março de 2018. 